\title{
Impact of Tutoring Method on Improving the Quality of Clinical Supervision in the Context of Nursing Education
}

\author{
Merabti Abdelilah, PhD Candidate \\ Elachqar Abdelrhani, PES \\ Squalli Houssaini Tarik, PES \\ Kaddari Fatiha, PES
}

University of Sidi Mohamed Ben Abdellah, Morocco

Doi: 10.19044/esj.2019.v15n6p139 $\quad$ URL:http://dx.doi.org/10.19044/esj.2019.v15n6p139

\begin{abstract}
This paper focuses on the impact of tutoring as a preferred method for clinical supervision of nursing students. The study was conducted by relying upon two main actors of this method, namely: the tutor and the tutored. The development of this work was based on comprehensive and analytical readings of previous work to highlight the effects of the tutoring method on the quality of clinical supervision of students. This work allowed us to appreciate the positive side of the impact of this method. Moreover, the analysis made at the end of this work and the figures obtained have allowed us to conclude that a start of tutoring will have significant benefits, mainly, for the tutor: teaching experiences, motivation, and development of critical thinking. Also for the tutored, it includes: the success of the training, the relational support, the construction of the professional identity, and the valorization.
\end{abstract}

Keywords: Impact, Tutoring, Nursing education, Tutor, Tutored

\section{Introduction}

In Morocco, nursing education applies the principle of alternation according to the Ministry of Health in 2015. This is because the education provided includes theoretical courses, tutorials, practical work, field work or project, and internships. According to Formaux, in 2002, practical internship is a valuable time for nursing education. Its aim is to enable students to apply their knowledge and know-how according to their level, learning, and respecting professional rules and values. Since competence can only be born in a clinical situation, Otti et al. (2015) stated that it is very important to pay 
particular attention to the quality of the clinical supervision of nursing students.

The literature describes the coaching offered to nursing students in the care units in a number of ways, such that there is mainly 'preceptorship', mentoring, and tutoring. Merabti et al. (2018) indicated that despite the fact that the three strategies are similar in their approaches, goals, stakeholders and benefits, the implementation of a coaching method by tutoring seems favorable for its success. Thus, this is in addition to its cognitive, metacognitive, and socio-emotional advantages of students and its adaptability to our context.

The present work explains the impact of the implementation of tutoring on the development of individual skills for learners (tutored) and supervisors (tutors) in nursing field. The development of this work is articulated as follows: a state of the art is presented in detail in the first part, then it is followed by a demonstration of the impact of tutoring in the second part, and finally an analysis to highlight the main benefits was the subject of the last part.

\section{Preceptorship, Mentoring and Tutoring}

The literature describes the clinical supervision of students in several forms (methods) and according to several speakers. To set an example, in France: the internship supervisor, the internship tutor, proximity professionals, and the referent of internship. In Quebec: The preceptor, the instructor, the tutor, the mentor, and the supervisor...

In this chapter, 'preceptorship' and mentoring are briefly studied as being among the main methods of clinical supervision of nursing students, whereas tutoring method is detailed since it seems mostly advantageous and highly adequate to our context. The development of this work was based on comprehensive and analytical readings of previous work to highlight the effects of the tutoring method on the quality of clinical supervision of students.

\section{1. 'Preceptorship' and Mentoring}

\subsubsection{The 'Preceptorship'}

According to the Canadian Nurses Association (CNA) in 2004, 'preceptorship' is a frequently used teaching and learning method in which nurses perform clinical role modeling. Preceptorship is in fact a period of time during which an experienced nurse helps a novice nurse or student to adapt to her/his new role and succeed in her/his new duties.

According to the Large Terminology Dictionary of the Office Québécois (2006), preceptorship is often used in the field of health to guide novices in the practice of their profession for a limited period. 
Duration and Goals of Preceptorship

The Canadian Nurses Association (CNA) (2004) stated that preceptorship is generally time-bound and applies in a specific work or learning context. Preceptorship is often used to acquire a basic level of knowledge, skills and personal qualities, as well as social integration into the profession or field of practice. However, in a preceptorship situation, a period of time is determined. For example, an employer may decide the period of time for a novice nurse to develop the skills of a new role for a new unit of care. Time periods for preceptorship tend to be short-term, usually one to two months. This period of time varies according to the type of participant, the context of implementation, and the targeted needs.

\section{Advantages of Preceptorship}

Lamoureux and Melançon (2014) announced that preceptorship is a teaching/learning method designed to help nurses acquire the necessary skills through direct and time-bound supervision. It allows the acquisition of a basic level of knowledge, techniques and personal qualities, as well as social integration into the profession or field of practice. Indeed, it helps to develop clinical judgment and knowledge. It also helps acquire professional autonomy more quickly, increases self-confidence, reduces stress, increases the sense of belonging, and gives access to positive role models.

Roles and Functions of the Preceptor

The Health and Social Services Center of the South-west Verdun (2008) specified that the preceptor is a nurse who has clinical expertise, who acts as a role model, who has the ability to assist the novice nurse in the application of the practice, and who is available for supervision. The roles and functions assigned to the preceptor are:

- To establish a partnership and a relationship of trust with the learners;

- Work with the learner to create experiences that helps them to effectively achieve their goals;

- Provides support when skills cannot be safely applied;

- Offer formative (continuous) and summative (final) feedback as needed on the progress of the objectives;

- Provides experiences to help the learner integrate socially into the profession;

- Generate regular and effective feedback from a perspective of continuous improvement of the preceptorship program. 


\subsubsection{Mentoring}

The MAB-Mackay Rehabilitation Center (2013) emphasized that mentoring is a relationship between a more experienced person (the mentor) and an individual who wants to improve their skills (the protégé or mentee). These two people once inter twinned form a dyad. Mentoring is necessarily based on mutual respect and is a relationship of support, learning, and exchange. It is a support relationship at the professional level, but it is also considered to be personal.

Guay and Lirette (2003) indicated that mentoring can be informal or formal. Informal mentoring is based on a natural relationship and spontaneous association. The mentee initiates the steps with the person he chooses as a mentor. He also communicates his expectations of the relationship. Formal mentoring involves a formal program that provides a structured approach, supported by the organization so that people who register can benefit from it. Organizations that implement formal programs generally aim to promote the career development of employees, their professional integration, and the development of skills relevant to the performance of their duties.

\section{Duration and Goals of Mentoring}

According to Bisson, in 2012, the relationship between the mentor and the student is based more on the needs of the person developing a new role or adapting to new functions. This relationship can vary from a few months to a few years. In fact, the duration is related to the time that the learner will take to achieve his / her goals. The main purpose of mentoring is to enable the learner to develop long-term career goals.

\section{Benefits of Mentoring}

Severson (2015) consider that the concept of mentorship is important to enable patients and their families to benefit from safe and ethical care provided by a skilled workforce. Other benefits of mentoring include: increased job satisfaction, the decrease in the need for recruitment, and the increase in the retention of nurses. Brunet (2009) specifies that the mentoring relationship is a relationship with the objective of allowing growth both from a professional and a personal point of view. On the other hand, Lamoureux and Melançon (2014) announced that mentoring consolidates the knowledge acquired, improves competence, increases confidence and security, reduces stress, brings satisfaction to work, and contributes to the development of clinical leadership.

\section{Qualities and Roles of the Mentor}

Guay and Lirette (2003) mentioned that a good mentor must have great interpersonal skills and be pedagogical. He must therefore have excellent 
listening and empathy, while keeping the necessary distances in order to let his mentee do his own learning. He must be able to provide constructive, positive and useful feedback, and therefore demonstrate good analytical and problem-solving skills. He must be reassuring and has the leadership to motivate his mentee, whose strengths and successes he recognizes. In addition, the mentor must be open to criticism; he must accept to put his ideas and methods back into question. Finally, the mentor must be a credible model for his mentee, and must honestly know how to establish a relationship of trust with the mentee.

\subsection{Tutoring}

\subsubsection{Definitions}

In reference to Boutet's article (2000), tutoring refers to a relationship of support for learning and identity development, established between an educator and a student.

The tutoring guide of the Ministry of Health of Morocco and Enfermeras Para el Mundo of Spain (2012) defines tutoring as a formative and/or normative professional relationship between two people, a professional and a learner, to discover a profession. Tutoring is a form of individualized help outside the classroom. Tutoring can be for a single student or group of students. Thus, the tutor can be a teacher, or another student "peer tutoring".

In other words, tutoring can be defined as a set of human and organizational means that a company puts in to integrate and train one or more learners in a work situation.

\subsubsection{Duration and Goals of Tutoring}

For Phaneuf (2013), the goals of having a tutor is to enable the student to recognize the difficulties, find new methods of acquiring knowledge, and to develop professional personality of the helped. Tutoring has a limited time frame, either during the training period or the duration of a learning activity. Tutoring can be used in a class group for the learning of knowledge or over a longer period, such as a work placement or the duration of a session.

\subsubsection{Benefits of Tutoring}

For Ridet (2016), tutoring, as part of a system of skills development, is a device that combines both training moments and working moments, and also the development of professional identity and whose tutor is in a support function. However, tutoring is a major element of socialization, transmission of values, appropriation of operational know-how, and skills development. The first intention of the tutoring, and the work of the tutor, is to accompany the student to the appropriation of the cognitive dimension by helping him to understand the interaction between action and reflection. Indeed, tutoring has 
three main functions: a pedagogical function, a socialization function, and a management and supervision function.

\subsubsection{Roles of Tutor}

Dugal (2006) lists five roles of the tutor:

1. Advise: Establish a relationship, help identify the origin of the problems.

2. Observer: Collect and analyze data, facilitate observation.

3. Provides feedback: Return "mirrored", illuminate his behavior.

4. Instructor: Provide knowledge, ideas, and examples.

5. Evaluator: To inform on the evolution of its progression.

\subsubsection{Main Functions of Tutoring}

According to Bastide (2013), tutoring has three main functions. Thus, the result of which depends largely on the devices implemented and also on the skills of the tutors.

\section{An Educational Function}

The essence of the tutorial function is often cited as the main objective of the device. The purpose of the educational function is to develop the skills of the tutor through his support in the work situation. It thus makes it possible to optimize the match between the expected skills and the real skills of the learner.

\section{A Socialization Function}

Frequently considered as a secondary benefit for the learner, the function of socialization, or social support, is nonetheless a major component to take into account in the organization of the device and the choice of tutors. Tutoring here proves to be a generator of social bonds. Thus, it maintains solidarity between the members of the same community. By formalizing exchanges based on a relationship of trust between the tutor and the tutored, tutoring allows the latter to access relational knowledge, ways of doing things and interact specifically with the service, thereby facilitating its integration.

\section{A Management and Supervision Function}

This function not only includes tasks of planning and organizing the integration and monitoring of new learners, but also coordination with the various professionals and stakeholders in learning. It also includes tasks related to supervisory practices, through an appropriate distribution of learners' work, by expressing requirements in terms of obedience, attendance, activity, and dress. 


\section{Impact of Tutoring on the Quality of Clinical Supervision}

Baudrit (2012) states that when they are on probation in health care institutions, nursing students are entrusted to caregivers who, as tutors, are assigned to accompany and evaluate them as part of their vocational training. Certainly this support will have an impact on the two main actors of the tutorial function namely: the tutored and the tutor.

\subsection{Impact on the Tutored}

\subsubsection{The Usefulness and Benefits of Tutoring}

The usefulness of tutoring is widely discussed by several authors. However, a literature review was developed by Chaliès et al. (2009) who focused on the contributions of tutoring on the emotional support of trainees (Clarke \& Jarvis-Selinger, 2005), their accompaniment in their confrontation with the reality of work (Hebert \& Worthy, 2001), constructing their identity (Durand, 2000; Wang et al., 2004; Williams et al., 2001), acquiring professional knowledge (Bertone et al., 2003; Chaliès et al., 2004; Hascher et al., 2004; Ponte et al., 2004; Zanting et al., 2003), and the development of their reflective practice (Parson \& Stephenson, 2005; Ward \& McCotter, 2004). Tutoring appears to be an essential component of training.

The impact of supervision on the future caregiver was studied by Chapuis et al. (2015) among 13 students and 4 tutors at the level of Cedex Besançon. The results revealed that, unanimously, the nurses graduates of State tutors surveyed believe that their supervision has an impact on the future caregiver. In view of their responses, the caregivers' caring attitude seems to positively influence student empowerment. Moreover, it is affirmed through this study that supervision by tutoring offered to nursing students has gradually allowed them to acquire the necessary professional positioning to carry out their missions.

Concerning the benefits of tutoring, a qualitative descriptive research carried out through interviews conducted by Chevrier (2006) at the University of Quebec in Montreal, with tutors and students, emphasized that almost all trainees interviewees considered that there are benefits to be framed. Firstly, they stated that the more tutors they have, the more rewarding the workshop would be because there is a possibility of learning from the different experiences and strengths of each. Secondly, trainees mention that being supervised allows them to always have a resource person to answer their questions and to give explanations. Thus, they declare that the tutors have allowed them to discover the various aspects of the profession and the responsibilities that flow from it. As a result, students have a better idea of their career choice.

According to Chevrier (2006), the students interviewed declared their satisfaction with the reception, availability, and trust shown by all tutors to 
them. In addition to the availability in terms of the freedom of time expressed by one of the trainees, availability in terms of willingness to help is also implied in certain student responses. Confidence, on the other hand, is reflected mainly based on the fact that the trainees feel that they are welcome in the training center because the tutors put them at ease and entrust them with the keys to the rooms. In addition, due to the attitude of the tutors, they are also part of the skills needed to take on the role of tutoring. All of the trainees make positive comments on their interpersonal relationships with their respective operational and hierarchical tutors. Hence, the relationship is then described as good, friendly, and cordial. This kind of situation is very rewarding for trainees and it has a positive effect on their self-esteem and confidence.

\subsubsection{Practices and Tutorial Interventions}

A research was conducted by Chomienne and Poellhuber at Cégep@distance in Quebec between 2003 and 2006. This research was mixed in nature using both a quasi-experimental design and a qualitative methodology based on individual interviews. Also, it made use of a multi-case study with a sample of 916 students on the effects of introducing three types of tutorial interventions on student motivation and perseverance. The results showed that the effect of tutoring measures on perseverance is significant. So, $72.0 \%$ of students in the individual tutoring sample continued to complete the training, while only $57.2 \%$ of those in the control group did so. The difference is also observed in the success rates, with the students benefiting from the tutoring interventions being $18.4 \%$ higher than the control group. In the interviews, students spoke extensively about relationships with tutors, and they are almost always positive. The welcome letter generated motivation and a sense of welcome and confidence.

Dugal (2006) conducted a study on the spontaneous attitudes that tutors tend to adopt towards trainees and their effects on initial training. The results showed that tutors mainly adopt three dominant attitudes:

Attitudes of Direct Influence (Evaluation, Decision, Support): They risk reducing the participation of the trainee: in terms of quantity (he expresses himself less) and quality (he only expresses himself in relation to what the tutor says). On the other hand, they can help reduce the trainee's anxiety; the latter will have the feeling that the tutor takes care of his problems (which in return can sometimes create a certain dependency).

Attitudes of Indirect Influence (Investigation, Interpretation): They seem to have more nuanced effects and a great variability in the effects produced according to the way they are used. Also, they facilitate progression to a solution built by the tutor. 
Attitude of Understanding: The latter, a little apart, probably favors the trainee's involvement. It allows to "hold council" with the trainee, rather than just give him advice. On the other hand, if this attitude becomes too rigid or too repetitive, the tutor confines himself to systematically reformulating the words of his interlocutor. This can lead to an inevitable frustration for the trainee.

The study by Chevrier (2006) showed that the students interviewed learned that the interventions of the tutors allowed them to carry out learning of various kinds such as: the technical aspects of the job and the operation of the internship institution, personal development, socialization, and career guidance. This learning was mainly possible thanks to three coaching practices used by the tutors that the students identified: questioning, demonstrating, and performing tasks which promoted their learning process. These three practices used by tutors promote reflection and experimentation and thus support students in their learning process. The results show that these practices, which are part of an experiential learning approach in the workplace, can effectively be described as best practices.

The results of an experimental research, with 105 university students in psychology and education sciences in Belgium, was conducted by Quintin (2007) whose goal is to identify the effects on student performance of the application of five modalities of tutorial intervention (reactive, proactive not targeted, targeted proactive - socio-emotional, pedagogical, or organizational). The results showed that there is a statistically significant overall difference between the modalities of tutorial intervention initiated by the tutor and those systematically carried out by the students in the context of learning activities (ANOVA test: F. 2.50, p. 0.047). Moreover, the averages of the scores obtained between the pre-test and the post-test ranged from $11.68 \%$ for the group reactively followed (the lowest average) to $39.80 \%$ for the students supervised proactively by targeted interventions, especially the socioemotional component (highest average). According to the assessment of the results of the students followed in a targeted proactive modality with regard to the pedagogical experience of the tutors (seniority), it is noticed that those who have been supervised by experienced tutors obtain better results (F. 5.339; p. 0.024). Tutors with greater pedagogical experience therefore seem to have been more effective, so students supervised by these tutors are more likely to achieve high results. Overall, this research has confirmed that the modalities of tutorial intervention, as effective as they are, explain only a part of the performances observed. Also, it is pointed out that other variables are involved in the progress made by students: previous academic results, tutors' pedagogical experience as well as factors related to motivation or commitment to training. 
Concerning the effects of tutoring practices used by tutors, the study by Chevrier (2006) revealed that trainees point out the questioning, the demonstration, and the performance of tasks as being the ones that favored their learning. More specifically, almost all of the students interviewed mention that being asked questions or asking for explanations about why such a gesture? How it works? What is the procedure to follow? etc. helped them to learn. This is because on the one hand, it encourages the trainee to think and analyze the situation. On the other hand, the questioning tests the trainee's knowledge and if necessary encourages him to reread his course notes to update or deepen his knowledge. These words of the students are confirmed by the tutors when they declared that they helped the trainees in their learning through sharing their experience of the trade with them. They also indicated that good communication/relationship between tutor and trainee promotes learning and helps to correct behaviors deemed non-professional by the trainee. Moreover, the majority of students consider that observing a tutor's demonstration helps them learn because observation allows them to understand the action, the process and to memorize it.

\subsubsection{Academic Success}

According to Duchesne and Larose (2000), several studies have dealt with the effects of tutoring on integration and academic success. Indeed, they indicated that the students who benefited from the tutoring show a better personal development and a greater satisfaction with regard to their school environment (Brown \& DeCoster, 1982; Cosgrove, 1986; Terrell \& Hassell, 1994; Tracey \& Sedlacek, 1985). Other studies have indicated that tutoring is associated with persistence in studies (Bishop \& Brenneman, 1986), academic success (Wilson et al., 1997) and increasing graduation rates (Frank \& Kirk, 1975).

For academic success, the results of the study by Duchesne and Larose (2000), among 148 at-risk students at Laval University, indicate that active control of tutors as perceived by them predicts student failure. Thus, it is plausible that by increasing control, the tutor responds to a high need for atrisk students to be better organized and structured. By behaving more authoritatively with students at risk, tutors would seek to fill this lack of organization and structuring. The use of control to help the student seems legitimate if one considers that the indices of control would be positively associated with the students' success.

In general, Alava and Clanet (2000) indicate that the objectives of a tutoring system are aimed at improving the success of learning, and also at reducing the drop-out rate by helping students to integrate. Therefore, it is a formative support system. 


\subsection{Impact on the Tutor}

Concerning the benefits of being a tutor, Chevrier (2006) reports that the tutors indicate that the trainees' presence brings them "fresh energy" by allowing them to learn from time to time new ways of doing things, for example; in a procedure, more theories, or to question and review operations. They also mentioned that supervising trainees allows them to update their knowledge and develop communicative skills, thus learning to transmit information better.

Dugal (2006), in his study pointed out that many tutors emphasized the enrichment generated by the exercise of this function. They noted, for example, the positive influence on their ability to listen to students and, consequently, on the greater attention given to their mistakes.

According to Bastide (2013), the contributions of tutoring include the following: it allows for the motivation and professional development of the tutor, the act of appointment of the tutor constituting a direct mode of recognition of his professional qualities, pedagogical and managerial.

In a study conducted by Alava and Clanet in 1997-1998, with 120 tutors to describe and explain the components of the tutorial action at the university, $47 \%$ said that tutoring is one of the ways to have teaching experience. Thus tutoring sessions are anticipated experiences of the teaching profession and a tutor is a future teacher. Indeed, seniority in the role of tutoring is taken as an asset in their activities. For tutors, tutoring activities are a preparation for the professions of education and, at the same time, it is a natural means of dialogue with others about their knowledge. Tutors experiment with coaching practices that are strongly deduced from their personal experiences. In the same vein, being a tutor is an opportunity to become familiar with the duties performed by teachers with sometimes temptations: "to be respected, to have responsibilities, to enjoy certain esteem".

According to Wittorski (1996), tutoring is not only a means of transmitting skills to others. It leads tutors to transform themselves as they apply new patterns of action that breaks with their usual professional practices. The tutors thus become jointly objective and serve as a means of transformation. These transformations include the production of new ways of seeing and thinking about work and practices. Thus the production of new action plans provides a link to transversal capacities (situation analysis, problem solving, and anticipation) and to new forms of management of their own capacities (analysis of practices, knowledge of their capacity for action). These are skills of the meta-skills process type. 


\section{Analysis}

From the literature, dealing with the impact of tutoring on the quality of clinical supervision of nursing students has been highlighted in several contributions compared to the tutorial function. These contributions mainly targeted the tutored and the tutors are interveners who are in action in this function. Indeed, these contributions usually offer, on the one hand for the tutored: learning, support, and success and on the other hand for the tutor, teaching experience, motivation, and learning.

In addition, Figure 1 and Figure 2 below represent the analysis of previous work on the impact of tutoring in order to focus on the main contributions as well as their percentages of citations. This analysis was done using the Microsoft Office Excel (2007) software.

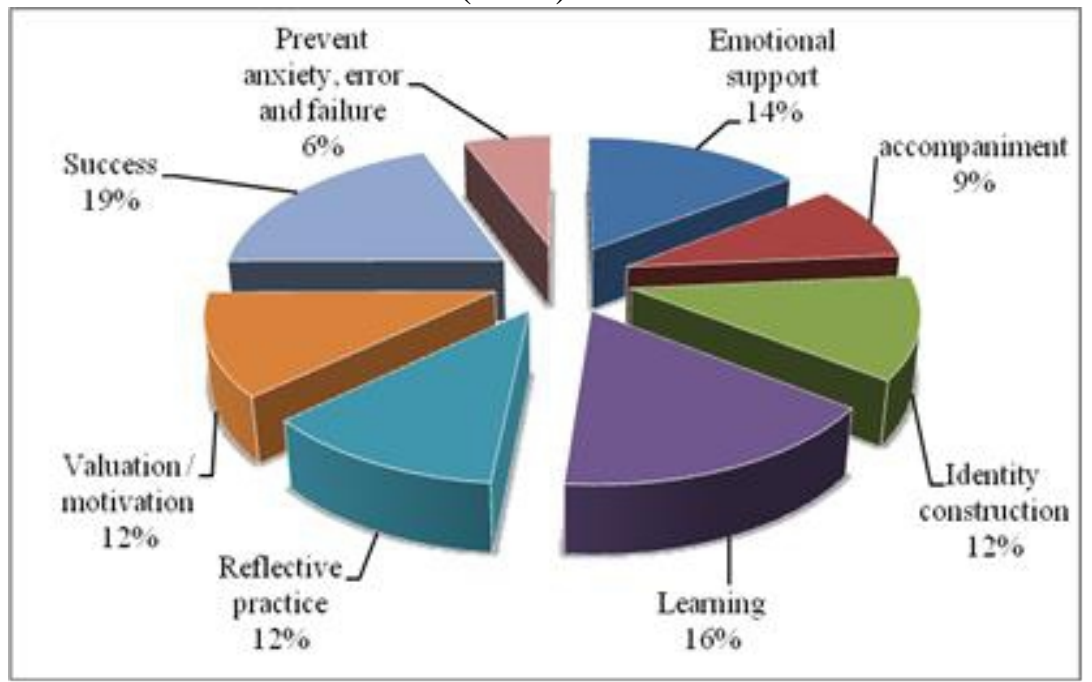

Figure 1. Impact on the tutored

According to Figure 1, we note that the impact of tutoring on the tutored is quite important and varied. Several aspects, therefore, of the positivity of this method on the learner are underlined by the literature. These cover the pedagogical, professional, and socio-emotional dimensions of the tutored. Thus, the results showed that the success of the training (19\%) remains the contribution of tutoring that is most mentioned by the authors. This is explained by learning achieved (16\%) and emotional support (14\%). In addition, other contributions were mentioned: the development of reflexive practice $(12 \%)$, the construction of professional identity (12\%), and motivation (12\%). 


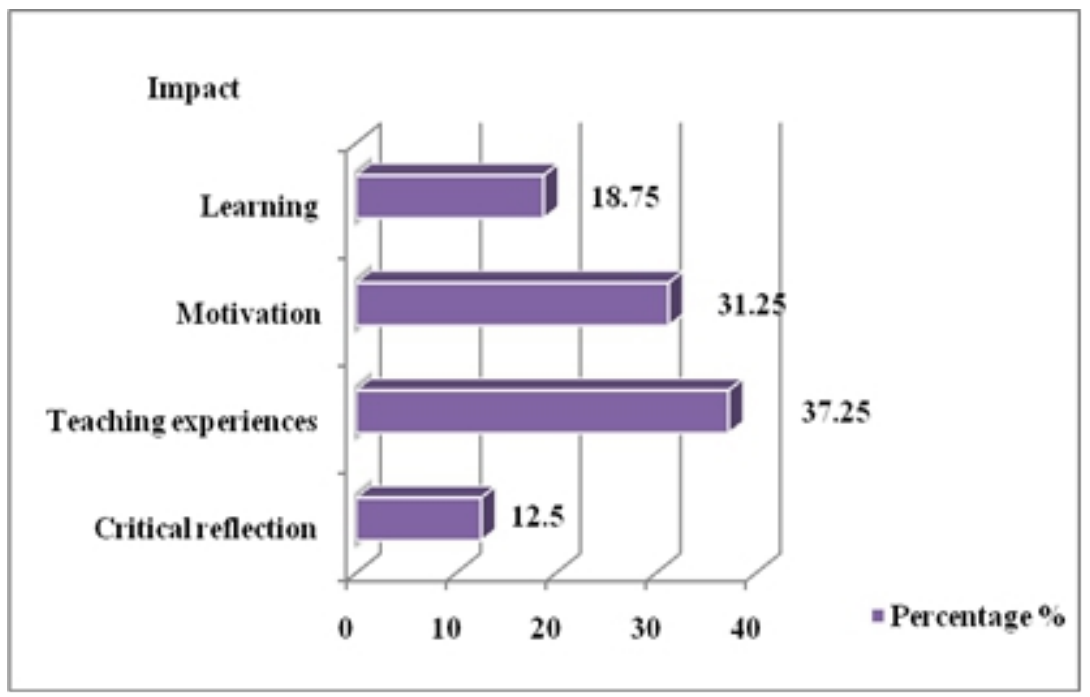

Figure 2. Impact on the tutor

The impact on the tutor has also been the subject of several studies. On his part, the tutor takes advantage of the tutorial function both in terms of the exercise of its professional functions and pedagogically. Figure 2 illustrates that by filling the roles of a tutor, the latter acquires teaching experience $(37.25 \%)$, communication skills, and subsequently preparation for the teaching profession. In addition to this, the tutor, during his accompaniment of the tutored, develops an intrinsic motivation $(31.25 \%$ ) which confers him a professional development. Critical reflection (12.50\%) is also developed in the tutor as long as he is supposed to have a critical look at his actions before the tutored.

\section{Conclusion}

In short, tutoring is not just a way to convey both practical and theoretical skills to a novice audience. The very exercise of tutoring engages the tutors in a dynamic of evolution of their technical and pedagogical knowhow as they initiate and experiment new procedures. This allows for the development and the blossoming of their professional postures. It is noted that the types of learning that trainees may have achieved through tutors affect acquisition, application, and transfer as well as the three different objectives of a work-study placement.

Finally, Bastide (2013) affirmed that the notion of tutoring has been strongly popularized in recent years in the professional nursing field. Tutoring has strong interests for the tutored, the tutor, the service, and the patients. A number of recommendations concerning the organization of the device can be formulated: learning path, tutor profile, monitoring, and evaluation tools. 
However, the main obstacles to this innovative organization can be overcome if they are correctly analyzed beforehand.

\section{References:}

1. Alava, S. \& Clanet, J. (2000). Elements for a better knowledge of the tutorial practices: crossed views on the tutor function. Review of Educational Sciences, 26 (3), 545-570. doi: 10.7202 / 000290ar

2. Bastide, T. (2013). Tutoring, an efficient practice. Pedagogy. Experience. N528 August/September 2013. Hospital management.

3. Baudrit, A. (2012). Today, be a tutor to nursing students: a complex and lasting mission? Nursing Research 2012/4 (N¹11), p. 6-12. DOI 10.3917/rsi.111.0006

4. Bisson, S. (2012). Development of a coaching project by tutoring to support the success of students with difficulties in nursing internships. Faculty of Education. Master's degree in college education. University of Sherbrooke.

5. Boutet, R. (2000). Tutoring: A modality of the teacher-student relationship. Collegiate pedagogy. Flight. 13 no 4

6. Brunet, Y. (2009). Development of a coaching guide for mentoring junior college teaching staff in college nursing. Essay submitted to the Faculty of Education for the title of Master of Education (M. Ed.). Master's degree in college education. University of Sherbrooke.

7. Canadian Nurses Association (2004). Achieve excellence in the practice of the profession; Preceptorship and Mentoring Guide. Ottawa: CNA.

8. Chaliès, S., Cartaut, S., Escalié, G. \& Durand, M. (2009). The usefulness of tutoring for young teachers: proof by 20 years of experience. Research and Training, 61/2009. Revues.org/534; DOI: 10.4000.

9. Chapuis, H., Girard, C., Graidia, N. \& Small, J. (2015). Supervision of nursing students in training and impact on the future caregiver. Institute of Training of Health Professionals. Nurse Training. Besançon Cedex.

10. Chevrier, N. (2006). Descriptive study of supervisory practices of tutors in companies that promote learning trainees in a program of vocational training alternately. Master's degree in Education. University of Quebec in Montreal.

11. Chomienne, M. \& Poellhuber, B. (2009). The effects of coaching and collaboration on motivation and perseverance. Educational research. Collegiate Pedagogy VOL. $22 \mathrm{~N}^{\circ} 2$.

12. Duchesne, S. \& Larose, S. (2000). The interpersonal behaviors of tutors-teachers and the integration of students in college studies. 
Journal of Educational Sciences, 26 (3), 571-600. doi: 10.7202 / 000291ar.

13. Dugal, JP. (2006). Tutors' attitudes and training effects. Tutoring and accompaniment. Workshop 1. Symposium. November 23-24, 2006

14. Formaux, V. (2002). Dress the supervision. Memory for graduation from health executive. Training Institute of Health Executives. Care sector. French Red Cross.

15. Guay, MM. \& Lirette, A. (2003). Guide to Mentoring for the Quebec Public Service. Revised Edition, Center of Expertise in Human Resources Management. Research report.

16. Health and Social Services Center (CSSS) of Sud-Ouest-Verdun (2008). Training guide for the nurse preceptor.

17. Lamoureux, I. \& Melançon, MJ. (2014). Nurse coaching program learning in a new field of activity: a guarantee of success. Colloquium of the ORIILL. North of Lanaudière Health and Social Services Center.

18. MAB-Mackay Rehabilitation Center (2013). Mentorship program.

19. Merabti, A., El Achqar, A., Squalli Houssaini, T. \& Kaddari, F. (2018). Comparative study of clinical supervision methods for nursing students. Laboratory of Didactics, Pedagogical Innovation and Curricular. Faculty of Sciences Dhar Mahraz Morocco.

20. Ministry of Health Morocco \& Enfermeras Para el Mundo Spain (2012). Tutorial guide for the follow-up of internships of midwifery students of the IFCS of the Kingdom of Morocco.

21. Ministry of Health Morocco (2015). Internal Regulations of the Higher Institutes of Nursing Professions and Health Techniques. Order $\mathrm{n}{ }^{\circ}$ 09/2015 of February 26, 2015.

22. Otti, A., Pirson, M. \& Piette, D. (2015). Perception of supervisors of the management process and the quality of clinical teaching supervision in nursing and midwifery in Benin. Nursing Research Association (ARSI). "Nursing research" 2015/4 N ${ }^{\circ} 123$. Pages 77 to 88. ISSN 0297-2964.

23. Phaneuf, M. (2013). Coaching, a tool at the service of teachers.

24. Quintin, JJ. (2007). The impact of tutoring on student performance. Effect of five methods of tutorial intervention on the performance of students engaged in asynchronous collective work. Jun 2007, NPRI, 2007. <hal-00161540>.

25. Ridet, L. (2016). Tutoring and professionalisation of nursing students. Contribution of learning situations to skills development. memory presented for the Professional Master's degree. University François Rabelais - Tours. 
26. Severson, C. (2015). Encourage mentoring through professional development Canadian Journal of Nursing in Oncology. Volume 25, Issue 2.

27. Wittorski, R. (1996). Evolution of the professional skills of tutors through the exercise of tutoring. The tutorial function in educational organizations and companies. Research and training. No. 22/1996. NPRI, ISSN: 0988-1824. ISBN: 2-7342 0542-4. 